\title{
Exploration on Real Time Interactive Teaching Reform of History of Physical Discovery Course in Post Epidemic Period
}

\author{
Yuan Wang ${ }^{1, *}$, Liping Huang ${ }^{2}$, Sanli Fu ${ }^{1}$, Xueyong Ding ${ }^{1}$, Liangcheng Wang ${ }^{1}$, \\ Liansheng Wang ${ }^{1}$
}

\author{
${ }^{1}$ School of technology, University of Sanya, China \\ ${ }^{2}$ Sanya No.1 Middle School, China \\ *Corresponding author. Email: wangyuan0155@163.com
}

\begin{abstract}
COVID-19 has changed the traditional "face-to-face" classroom teaching mode, and the "online and offline" combination of real-time interactive teaching has become the main teaching mode. In line with the "student-centered" education concept, the new teaching requirements of "rich resources, clear tasks, timely feedback and effective interaction" are put forward. By using MOOC resources, learning guidance materials, "preview + teaching + practice" courseware and other teaching resources, students are guided to carry out autonomous learning before and after class, and real-time interaction of "online and offline" is carried out in the classroom teaching, serving students in the classroom and in the cloud. Through the implementation of teaching reform and the analysis of students' curriculum assessment results, the effectiveness of students' learning has been improved compared with previous years, students' learning methods and learning ability have been improved, and the teaching quality of real-time interactive teaching and classroom teaching has basically achieved the goal of substantial equivalence.
\end{abstract}

Keywords: Real time interactive teaching, History of physical discovery, Student-centered, Teaching reform.

\section{INTRODUCTION}

The biggest characteristic of traditional classroom teaching mode is that teachers and students carry out face-to-face teaching in the same space and time. This kind of teaching mode has a strong sense of ceremony for teachers[1]. Teachers can feel the students' learning state directly and in real time through their own eyes, ears and other senses[2]. At the same time, with the help of information technology such as "Rain Classroom" to carry out interactive links such as question answering and discussion, teachers can grasp the overall learning effect and teaching quality of students in real time[3,4]. In addition, from the perspective of students, the traditional classroom is the most familiar mode in their more than ten years of learning process. Students have a strong environmental effect in the classroom. They can feel the pressure and tension brought by teachers, and can also feel the peer role between classmates. Based on the above laws of pedagogy and teaching costs, online courses, which are gradually popular in recent years, can not replace the physical schools and actual classrooms, but are only implemented in some tutorial courses and minor courses. However, COVID-19 in the spring of 2020 leads to the fact that college students can not return to school according to the opening time of the school. In order to ensure the teaching quality of the course, all colleges and universities adopt various forms of online synchronous teaching $[5,6]$. On the basis of the early "hybrid" teaching reform, aiming at the opportunity of some students returning to school and some students not returning to school, this paper uses information-based teaching means and rich teaching resources to carry out the reform of "online and offline" real-time interactive teaching mode, so as to achieve the teaching effect of real-time interactive classroom and traditional classroom. 


\section{NEW REQUIREMENTS OF REAL TIME INTERACTIVE TEACHING}

The biggest difference between real-time interactive teaching and traditional classroom teaching is that teachers and students are in different space or in different time and space under special circumstances. The difference of space leads to the problems of "no sense of object" and no real-time feedback from students, while the peer effect of "no sense of pressure" and mutual promotion among students exists at the student level. Therefore, the author believes that based on the "studentcentered" online teaching process, we should put forward new requirements in four aspects: rich resources, clear tasks, timely feedback and effective interaction.

\subsection{Rich Resources}

As the basis of intelligent teaching, teaching resources with various forms and rich contents are indispensable. Therefore, teachers need to combine MOOCS, pre class guided learning materials (referred to as "learning guidance"), exercise bank, courseware, virtual simulation program and other contents organically, so as to enable students to learn better without reducing the difficulty of the course.

\subsection{Clear Tasks}

It is necessary to put forward clear learning tasks for students, including pre class preview task, classroom learning task and after class practice task; at the same time, it is necessary to combine the clear tasks with the curriculum assessment system, so that students with high interest in learning have a clear learning direction, which can also increase the learning motivation of students with poor interest in learning, and improve the learning enthusiasm of students at all levels.

\subsection{Timely Feedback}

Timely feedback. According to the learning tasks assigned by teachers, we should be able to give students timely and accurate feedback to enhance the authenticity of teachers and students' teaching and learning, including pre class preview test results, classroom learning test results, and after class exercise homework results. The feedback of pre class preview results can guide students to pay more attention to class, and help teachers master the difficulties of students' preview in advance and adjust the class emphasis of the teaching content. The results of classroom learning can help students understand their own learning effect, help students improve their sense of learning achievement or urge students to improve their learning motivation. At the same time, it can also help teachers master the overall learning effect of students in time, or adjust the teaching progress, and explain the learning difficulties of students more deeply. The results of after class exercises can help students master their own learning effectiveness, enhance their sense of achievement or enhance their learning motivation, and also help them understand their ability to solve complex problems. They also can help teachers master the effectiveness of teaching design and teaching reform, which provides a strong basis for the design of follow-up teaching content and the next round of teaching reform.

\subsection{Effective Interaction}

In order to urge students to strengthen learning and enhance learning motivation, it is necessary to implement effective interaction in all aspects of teaching, including in class and out of class. In the classroom, through the information technology means of the teaching platform, we can carry out the unified interaction of the whole staff and individual interaction, and the content of the interaction must be closely around the teaching theme, and the form of interaction should serve for "timely feedback". The interaction outside the classroom is carried out in the form of "one class, one group" QQ group and students' online learning platform. The content is mainly task release, problem discussion, homework talk, tutoring and answering. It solves the unsolved problems in the classroom, students' difficulties in the learning process, and discusses the frontier knowledge not involved in the classroom, so as to enhance the emotion and friendship between teachers and students.

\section{THE GOAL AND MODE OF REAL TIME INTERACTIVE TEACHING}

Real time interactive teaching objective: through the redesign of teaching mode, the teaching quality of teaching and classroom teaching is essentially equivalent. Real time interactive teaching mode: partial flipped teaching mode is adopted, part of the teaching content (course introduction part and course expansion part) is moved to the pre class, which is presented in the form of MOOCS short video and electronic teaching materials, with test assignments for pre class preview. The main content of classroom teaching is live broadcast, which is presented in the form of courseware, timely test, discussion and $\mathrm{Q} \& \mathrm{~A}$; the unfinished content of classroom, after-school exercises and other content are carried out in the form of after-school autonomous learning. At the same time, with the help of tutoring and answering session, we can carry out problem discussion, homework talk, tutoring and answering to help students cross the knowledge gap.

\section{CURRICULUM IMPLEMENTATION}

\subsection{Choice of Teaching Platform}

In order to ensure that teachers and students can normally carry out real-time interactive teaching after the beginning of school, online teaching test is carried out 
before the beginning of school to ensure that teachers and students can correctly use all kinds of classroom functions and solve the problems of equipment, technology, network and so on that may appear in the teaching process. After the preliminary network test and the actual opening experiment, considering the advantages and disadvantages of various information technology platforms in the process of live course, the combination of "Rain Classroom + Tencent Classroom" is adopted. Rain Classroom in the process of teaching, with voice broadcast, limited time answering, bullet screen, contribution, roll call and other functional advantages, can help teachers grasp the overall learning effect of students in real time, at the same time after class will carry out classroom data analysis, help teachers analyze the learning effect of each student, truly achieve "student-centered". According to the needs of online teaching, teachers need to communicate with students in real time. Therefore, Tencent classroom with "look back" function is selected for video live broadcast, so that teachers and students can realize "face-to-face" communication and transfer information, and ensure the sense of ceremony and immediacy in the classroom.

\subsection{Preparation of Teaching Resources}

In order to ensure the realization of the goal of "rich resources", according to the theoretical teaching part of the course and the construction requirements of the firstclass undergraduate course, the teaching resources are prepared around the curriculum outline, including: teaching courseware, teaching cases, classroom questioning, homework exercises, selection of highquality online video resources, etc. According to the needs of the course, we should consider the achievement of the teaching goal of learning achievement orientation, reasonably arrange the learning content and training materials that are helpful for students to "construct knowledge independently" in advance, and guide students to use basic knowledge for practical application. The teaching courseware includes three parts: preview courseware before class, lecture courseware in class and practice courseware after class. All teaching links are included to cultivate students' good learning habits and learning autonomy.

\subsection{Preview before Class}

Aiming at the goal of "clear task" before class, through the "mobile courseware" function in the Rain Classroom, the preview courseware of the course is designed. At the same time, there are multiple-choice questions and blank filling questions for knowledge mining and simple application after each video, so as to put forward the clear learning task before each class and investigate the effect of students' preview. The Rain Classroom can count the students' answers Teachers can know in detail the macro data of each knowledge point, and also know whether each student preview and the micro data of each question. Through the macro data, we can get which knowledge points students have poor learning effect, and then guide the focus of online classroom teaching content, improve the efficiency of classroom learning; through the micro data, we can get which students' learning habits and learning results are poor, and then help teachers accurately carry out academic assistance, improve the learning effect of backward students, and realize the "harmony" between teachers and students before class "Feedback" and "effective interaction".

\subsection{Classroom Teaching}

Aiming at the goal of "effective interaction" in class, the classroom adopts the teaching form of "Rain Classroom + Tencent Classroom". In the teaching content, the introduction part of the course and the basic concepts are moved to preview before class, which saves time for all kinds of interaction in online classroom teaching. At the same time, according to the students' Preview answer situation, the teaching content is adjusted pertinently, focusing on the students' understanding of difficult knowledge and the application of knowledge, with limited time answer, bullet screen discussion and real-time contribution to carry out "effective" teaching in class "interaction" and "timely feedback". For the knowledge and application part of the key assessment, the limited time answer can effectively urge the students to listen to the class seriously and master the students' learning effect effectively. By anonymous real-time contribution of students' answering process, teachers can effectively grasp the students' errors, and analyze the errors in the process of students' answering, so as to effectively help students break the thinking barriers and solve common problems. And for the content of students' more mistakes and the content that students click "don't understand", teachers can find the weakness of the courseware after class, and then further optimize and adjust the content of the courseware to facilitate students' understanding.

\subsection{After Class Practice}

Aiming at the goal of "timely feedback" after class, the homework after class is arranged to student in Rain Classroom through the function of "test paper". The objective question system will be automatically corrected. Teachers only need to correct the exercise questions presented in the form of subjective questions in time. Student can check the scores and answers of the questions on the mobile phone in time to make up for the loopholes in their studies. Teacher can effectively grasp the learning effect of students on knowledge through homework after class, so as to build this invisible and effective interaction between teachers and students. At the same time, in order to help students better grasp the 
logical relationship between what they have learned, students are required to summarize their own classroom notes and improve their ability to summarize knowledge.

\subsection{Tutoring, Answering and Periodic Testing}

In view of the homework with more mistakes in the homework after class, the paper uses the guidance and answer link to explain the wrong homework in a centralized way, which helps students break through the difficulties and solve the difficulties in learning. Through the use of tutoring answers to carry out the phased test, help students to test their own phased learning results, and form peer effect.

\subsection{Course Assessment}

According to the plan of the syllabus, in order to test the overall effect of students' learning, online course assessment is carried out in the Rain Classroom platform. In order to enable students to better carry out the assessment in the online environment, the assessment test in the same environment was carried out in advance to help students get familiar with the function and submission process of the Rain Classroom technology platform, so as to ensure that all candidates can carry out the examination smoothly. At the same time, because of the particularity of online examination, we agreed with the students before the examination "online examination ethics", and required the students to take the examination according to the agreement. The content of the test paper is all in the form of subjective questions, a total of 8 questions. Students are required to answer the questions on the draft paper and have a detailed problem-solving process, and then take photos to upload the system and submit the answers. After each question, there are detailed scoring standards. After the examination, students can view the scoring standards and master their own learning effect. Teacher conduct online marking in the Rain Classroom platform.

\section{CONCLUSION}

During the epidemic period, in the case that some teachers and students cannot carry out face-to-face education, the requirements of curriculum saturation, depth and academic tension are implemented through the real-time interactive teaching reform of "online and offline" combination. Using the platform of " Rain Classroom + Tencent Classroom", through adjusting the teaching content and teaching mode, sorting out the course resources, carrying out three teaching links: pre class preview, classroom teaching and after class practice, and combining with office hour time to carry out counseling and answering to help students better grasp the content. We should implement the requirements of the Ministry of education that "teaching and learning are suspended without stopping" and strive to achieve the substantial equivalence between online synchronous teaching and classroom teaching.

\section{ACKNOWLEDGMENTS}

Yuan Wang was partially supported by Hainan Provincial Department of Education (Hnjg2021zd-42) and Enterprise Cooperation Project of University of Sanya (USYXQ20-2). Xueyong Ding was partially supported by Hainan Provincial Department of Education (Hnjg2019zd-23). Liangcheng Wang was partially supported by Hainan Provincial Department of Education (Hnjg2021-100).

\section{REFERENCES}

[1] Jian Zhang, Yucai Zhou. Study on interactive teaching laboratory based on virtual reality $[\mathrm{J}]$. International Journal of Continuing Engineering Education and Life Long Learning,2020,30(3).

[2] Chien-Yu Lin, Chien-Chi Lin, Ci-Jie Chen, MeiRong Huang. Real-Time Interactive Teaching Materials for Students with Disabilities[A]. Intelligent Information Technology Application Association. Future Communication, Computing, Control and Management(ICF4C 2011 LNEE 142)[C].Intelligent Information Technology Application Association,2011:7.

[3] Shuai-guo WANG. Rain Classroom: The Wisdom Teaching Tool in the Context of Mobile Internet and Big Data[J]. Modern Educational Technology,2017,27(05):26-32.

[4] Jianyun Chen. Rain Classroom Helps Blended Online Teaching of Civil Procedure Law A[J]. International Journal of Social Science and Education Research,2021,4(1):58.

[5] Guo Nan. Study on the Teaching Practice of Foreign Journalism History Based on Rain Classroom during the COVID-19 Pandemic[J]. Advances in Higher Education,2020,4(4):2135.

[6] Xinjie Yu.From Interaction to Hybrid:The Response of Higher Education to COVID-19[J]. Proceedings of the CSEE,2020,40(20):6411. 